\author{
В. Н. Веремеев
}

Гомельский государственный университет им. Ф. Скорины

\title{
СТРУКТУРА БИОМАССЫ ПОЧВЕННОЙ МЕЗОФАУНЫ \\ В УСЛОВИЯХ ДИНАМИКИ РАЗНООБРАЗИЯ РАСТИТЕЛЬНОСТИ ПОЙМЕННЫХ ЛУГОВ ЮГО-ВОСТОКА БЕЛАРУСИ
}

Приведены сравнительные данные по составу и биомассе почвенной мезофауны в зависимости от биоразнообразия растительности пойменных лугов в условиях антропогенного воздействия. Установлено, что на пойменных лугах при увеличении разнообразия растительности имеется тенденция к увеличению биомассы почвообитающих беспозвоночных.

\section{В. Н. Веремєєв}

Гомельський державний університет ім. Ф. Скорини

\section{СТРУКТУРА БІОМАСИ ГРУНТОВОЇ МЕЗОФАУНИ В УМОВАХ ДИНАМІКИ РІЗНОМАНІТТЯ РОСЛИННОСТІ ЗАПЛАВНИХ ЛУК ПІВДЕННОГО СХОДУ БІЛОРУСІ}

Наведено порівняльні дані відносно складу та біомаси грунтової мезофауни залежно від різноманіття рослинності заплавних лук в умовах антропогенного впливу. Встановлено, що на заплавних луках при збільшенні різноманіття рослинності проявляється тенденція до збільшення біомаси грунтових безхребетних.

\author{
V. N. Veremeev \\ F. Scorina Gomel' State University
}

\section{BIOMASS STRUCTURE OF SOIL MESOFAUNA UNDER CONDITIONS OF DYNAMICS OF VEGETATION DIVERSITY OF FLOODPLAIN MEADOWS IN THE SOUTHEAST OF BELARUS}

Comparative data on structure and biomass of soil mesofauna depending on a biodiversity of vegetation of inundated meadows under conditions of anthropogenic influence are presented. By augmentation of vegetation diversity on meadows there is a tendency of increse of a biomass of soil invertebrates.

\section{Введение}

Показатели биомассы почвообитающих беспозвоночных, в том числе почвенной мезофауны, являются одними из важнейших характеристик, определяющих их роль в наземных экосистемах и, особенно, в почвах пойменных лугов [1; 2]. Исследование почвенных беспозвоночных луговых экосистем осуществлялось рядом исследователей, но биоразнообразие луговой растительности в условиях антропогенного воздействия в них практически не учитывалось [3; 4]. Ввиду этого изучение биомассы почвенных 
беспозвоночных в зависимости от разнообразия растительности пойменных луговых экосистем представляет определенный практический и теоретический интерес.

\section{Материал и методы исследований}

Изучение почвообитающих беспозвоночных проводилось в пойменной экосистеме в правобережье реки Сож выше впадения реки Ипути на широкой плоской равнине восточнее д. Поколюбичи Гомельского и Ветковского районов Гомельской области в 2006-2008 годах.

Данные по составу и биомассе основных групп основывались на материале почвенно-зоологических исследований, выполненных по стандартной методике [5]. Пробы брались размером $25 \times 25$ см и глубиной 40 см в каждом биотопе в 32-кратной повторности. Изучались состав и биомасса основных групп почвенной мезофауны в четырех биотопах, отличающихся уровнем антропогенной нагрузки и биоразнообразием растительности: пойменный луг нормального увлажнения, мелиорированный польдерный луг, берег мелиоративного канала, распаханный пойменный луг.

Пойменный луг нормального и временно избыточного увлажнения имеет рельеф плоский, ровный. Почва луговой экосистемы аллювиально-дерновая, слаборазвитая, песчанисто-рыхлосупесчаная. Проективное покрытие растительности - 95 \%, из которых вейника, лисохвоста и полевицы $65 \%$, мятлика лугового $20 \%$. Всего встречен 21 вид покрытосеменных растений.

Польдерный луг представляет мелиорированную площадь польдерной мелиоративной системы «Поколюбичи» с предупредительным шлюзованием в пойме р. Сож в Гомельском и Ветковском районах Гомельской области. На польдерном лугу почва дерново-подзолистая. Рельеф плоский, ровный. Проективное покрытие растительности $95 \%$, из которых вейника и лисохвоста $60 \%$, мятлика лугового $25 \%$, полевицы $5 \%$. Всего отмечено 17 видов.

Берег канала имеет повышенный рельеф. Почва образовалась за счет выброса земли из русла канала. Проективное покрытие растительности - $90 \%$, из которых осоки $45 \%$, мятлика лугового $10 \%$, лопуха большого $10 \%$, и лисохвоста $8 \%$. Всего встречено 14 видов.

Распаханный пойменный луг имеет плоский, ровный рельеф. Почва дерновоподзолистая среднесуглинистая, слабокислая. Основа травостоя - ячмень двухрядный. Кроме того, зарегистрированы единичные экземпляры сурепки полевой, полевицы, мятлика лугового, пырея ползучего. Всего 5 видов.

При описании биотопов, определении биоразнообразия растительности использовались методики, консультации и материалы Л. М. Сапегина и Н. М. Дайнеко [6; 7], за что автор выражает им глубокую признательность. Статистическая обработка материалов проводилась с использованием статистических пакетов Statistica 6.0, SPSS 13.0 for Windows. Биомассу определяли по фиксированному в 4 \% формалине материалу [8].

\section{Результаты и их обсуждение}

Изучение состава и биомассы почвообитающих беспозвоночных пойменной экосистемы показало, что наибольшая ее величина отмечается на пойменном лугу нормального увлажнения (более $33 \Gamma^{2} \mathrm{M}^{2}$ ). Основную часть биомассы составляют дождевые черви (5 видов), на долю которых приходится более 95 \% биомассы почвообитающих беспозвоночных данного биотопа. Наибольшая биомасса у дождевого червя Apporrectodea caliginosus (Savigny, 1826) - более 20 г/м². В 3 раза меньше биомасса Lumbricus rubellus (Hoffmeister, 1843). Значительно меньшей биомассой отличаются 
виды A. longus (Ude, 1826) и A. roseus (Savigny, 1826). Редко встречается Dendrodrilus rubidus (Eisen, 1874), биомасса которого менее 1 г/м². Биомасса остальных групп почвообитающих беспозвоночных невелика. Биомасса жесткокрылых по сравнению с дождевыми червями в 90 раз меньше. Среди них доминируют щелкуны и жужелицы. Наименьшей биомассой отличаются паукообразные (табл. 1).

Таблий 1

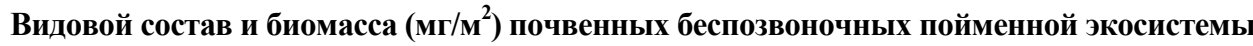

\begin{tabular}{|c|c|c|c|c|}
\hline $\begin{array}{c}\text { Таксономическая группа } \\
\text { беспозвоночных }\end{array}$ & $\begin{array}{c}\text { Мелиори- } \\
\text { рованный } \\
\text { польдерный луг }\end{array}$ & $\begin{array}{c}\text { Распа- } \\
\text { ханный пой- } \\
\text { менный луг }\end{array}$ & $\begin{array}{l}\text { Берег мелиора- } \\
\text { тивного канала }\end{array}$ & $\begin{array}{c}\text { Пойменный луг } \\
\text { нормального } \\
\text { увлажнения }\end{array}$ \\
\hline \multicolumn{5}{|l|}{ Lumbricidae } \\
\hline Apporrectodea longus (Ude, 1826) & 0 & $1017 \pm 404$ & $2741 \pm 980$ & $3310 \pm 2278$ \\
\hline Apporrectodea caliginosus (Savigny, 1826) & 0 & $6445 \pm 905$ & $2577 \pm 787$ & $20008 \pm 2089$ \\
\hline Apporrectodea roseus (Savigny, 1826) & 0 & 0 & 0 & $3080 \pm 992$ \\
\hline Lumbricus rubellus (Hoffmeister, 1843) & $5807 \pm 1265$ & 0 & $4572 \pm 1044$ & $5875 \pm 1821$ \\
\hline Dendrobaena octaedra (Savigny, 1826) & $2853 \pm 1079$ & 0 & 0 & 0 \\
\hline Dendrodrilus rubidus (Eisen, 1874) & 0 & 0 & 0 & $957 \pm 324$ \\
\hline Коконы Lumbricidae & 0 & 21 & 0 & $42 \pm 12$ \\
\hline Aranea & $5 \pm 2$ & $83 \pm 48$ & $26 \pm 16$ & $15 \pm 11$ \\
\hline \multicolumn{5}{|l|}{ Coleoptera } \\
\hline Curculionidae & $169 \pm 55$ & 0 & 0 & 11 \\
\hline Sitona sp. Germar, 1817 & $169 \pm 55$ & 0 & 0 & 11 \\
\hline Nitidulidae & 13 & 0 & 0 & 0 \\
\hline Meligethes Stephens, 1830 & 13 & 0 & 0 & 0 \\
\hline Byrrhidae & 0 & 0 & $49 \pm 36$ & 0 \\
\hline Byrrhus pillula Linnaeus, 1758 & 0 & 0 & $49 \pm 36$ & 0 \\
\hline Elateridae & $912 \pm 161$ & $320 \pm 72$ & $549 \pm 141$ & $229 \pm 99$ \\
\hline Agriotes obscurus Linnaeus, 1758 & $912 \pm 161$ & $320 \pm 72$ & $504 \pm 105$ & $91 \pm 31$ \\
\hline A. sputator Linnaeus, 1758 & 0 & 0 & 12 & 0 \\
\hline A. lineatus Linnaeus, 1767 & 0 & 0 & $33 \pm 24$ & $50 \pm 36$ \\
\hline Lacon murinus, Linnaeus, 1758 & 0 & 0 & 0 & 88 \\
\hline Carabidae & $143 \pm 85$ & $74 \pm 40$ & $99 \pm 52$ & $104 \pm 49$ \\
\hline Amara plebeja Gylleman, 1810 & $29 \pm 20$ & 0 & $12 \pm 8$ & 0 \\
\hline A. ingénue Duftsmitt, 1812 & 0 & 0 & 0 & $54 \pm 37$ \\
\hline Harpalus calceatus Duftsmitt, 1812 & 62 & $35 \pm 19$ & 82 & 0 \\
\hline Elaphrus riparius Linnaeus, 1758 & 0 & 0 & 5 & 0 \\
\hline Broscus cephalotes Linnaeus, 1758 & 37 & 39 & 0 & 30 \\
\hline Agonum obscurum Herbst, 1784 & $11 \pm 8$ & 0 & 0 & $20 \pm 9$ \\
\hline Clivina fossor Linnaeus, 1758 & 4 & 0 & 0 & 0 \\
\hline Staphylinidae & $72 \pm 32$ & 0 & 16 & 16 \\
\hline Cantharidae & 5 & 0 & 0 & 0 \\
\hline Cantharis rusitca Fallén, 1807 & 5 & 0 & 0 & 0 \\
\hline Coccinellidae & 0 & $18 \pm 11$ & $19 \pm 14$ & 0 \\
\hline Chilocorus bipustulatus Linnaeus, 1758 & 0 & 0 & $19 \pm 14$ & 0 \\
\hline Coccinella septempunctata Linnaeus, 1758 & 0 & $18 \pm 11$ & 0 & \\
\hline \multicolumn{5}{|l|}{ Diptera } \\
\hline Tabanidae & 0 & 0 & 0 & 40 \\
\hline Tipulidae & 0 & 88 & 0 & 0 \\
\hline \multicolumn{5}{|l|}{ Lepidoptera } \\
\hline Noctuidae & 0 & 0 & 255 & 0 \\
\hline Ectypa glyphica Linnaeus, 1758 & 0 & 0 & 255 & 0 \\
\hline
\end{tabular}

На берегу мелиоративного канала биомасса почвообитающих беспозвоночных по сравнению с пойменным лугом в 3 раза меньше. Здесь так же, как и на пойменном 
лугу, основу фауны составляют дождевые черви (более 90 \% всей биомассы почвооби-

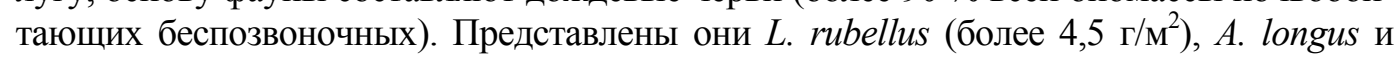
A. caliginosus. Около 7 \% биомассы приходится на жесткокрылых, среди которых наибольшей биомассой отличаются щелкуны с массовым видом Agriotes obscurus Linneus, 1758. Биомасса остальных групп (чешуекрылых и, особенно, паукообразных) невелика.

Биомасса почвообитающих беспозвоночных на мелиорированном польдерном лугу примерно такая же, как и на берегу мелиоративного канала. Как и в предыдущих биотопах, преобладают дождевые черви, представленные двумя видами (L. rubellus и D. octaedra, встреченного только в этом биотопе). Биомасса жесткокрылых в 6,5 раза меньше, как и на берегу мелиоративного канала, среди них преобладают щелкуны с тем же массовым видом A. obscurus. Наименьшей биомассой отличаются паукообразные.

На распаханном пойменном лугу биомасса почвообитающих беспозвоночных примерно такая же, как и на мелиорированном польдерном. Как и в других биотопах, максимальна биомасса дождевых червей (более 90 \% биомассы почвообитающих беспозвоночных). Представлены они двумя видами. Биомасса жесткокрылых по сравнению с польдерным лугом значительно меньше, преобладают также щелкуны с доминантным видом A. obscurus, относящимся к группе злаковых щелкунов и являющимся вредителем сельского хозяйства. Наименьшей биомассой отличаются паукообразные и двукрылые.

Исследование состава фауны почвенных беспозвоночных показало, что основу биомассы составляют дождевые черви, биомасса и разнообразие которых максимальны на пойменном лугу нормального увлажнения, значительно меньше биомасса жесткокрылых, среди которых преобладают щелкуны.

Анализируя фауну беспозвоночных и разнообразие растительности, следует отметить, что общая биомасса почвообитающих беспозвоночных в обследованных биотопах колеблется от 8,14 до 33,69 г/м², то есть в 4,1 раза (табл. 2). Биоразнообразие покрытосеменных растений изменяется от 5 до 21 вида или в 4,2 раза, то есть величины колебаний этих показателей примерно одинаковы. При этом наибольшее видовое разнообразие растительности - на пойменном лугу нормального увлажнения. Что же касается наименьшего разнообразия растительности, которое имело место на распаханном лугу, засеянном ячменем, то оно также совпадает с наименьшими величинами биомассы беспозвоночных.

Таблица 2

Биомасса (мг/м²) основных групп почвенных беспозвоночных пойменной экосистемы

\begin{tabular}{|l|c|c|c|c|}
\hline \multicolumn{1}{|c|}{ Беспозвоночные } & $\begin{array}{c}\text { Распаханный } \\
\text { пойменный луг }\end{array}$ & $\begin{array}{c}\text { Мелиорированный } \\
\text { польдерный луг }\end{array}$ & $\begin{array}{c}\text { Берег } \\
\text { мелиоративного } \\
\text { канала }\end{array}$ & $\begin{array}{c}\text { Пойменный луг } \\
\text { нормального } \\
\text { увлажнения }\end{array}$ \\
\hline Lumbricidae & $7483 \pm 650$ & $8660 \pm 1405$ & $9890 \pm 861$ & $33272 \pm 2720$ \\
\hline Ararei & $83 \pm 48$ & $5 \pm 2$ & $26 \pm 16$ & $15 \pm 11$ \\
\hline Coleoptera & $481 \pm 92$ & $1314 \pm 164$ & $732 \pm 134$ & $360 \pm 147$ \\
\hline Diptera & 0 & 0 & 0 & 40 \\
\hline Lepidoptera & $8135 \pm 656$ & $9979 \pm 1415$ & $10903 \pm 871$ & $33687 \pm 2723$ \\
\hline $\begin{array}{l}\text { Общая биомасса } \\
\text { беспозвоночных }\end{array}$ & 14 & 17 & 21 \\
\hline $\begin{array}{l}\text { Видов покрытосе- } \\
\text { менных растений }\end{array}$ & 5 & 0 & 255 & 0 \\
\hline
\end{tabular}

Анализ зависимости биомассы почвообитающих беспозвоночных от видового разнообразия растительности показал, что связь между этими признаками имеет нели- 
нейный характер. Квадратическое уравнение регрессии биомассы беспозвоночных $Y=26,0-4,71 x+0,24 x^{2}$ описывает более $93 \%$ разброса значений переменной $x$ (разнообразие растительности), а кубическое уравнение $Y=11,38-0,16 x^{2}+0,10 x^{3}$ описывает $96 \%\left(R^{2}=0,96\right)$ полученных данных. Приведенные нелинейные регрессионные модели характеризуются высокими величинами коэффициента детерминации $\left(R^{2}\right)$ и $F$-критерия Фишера. По мере увеличения биоразнообразия растительности пойменных луговых экосистем имеется тенденция увеличения биомассы почвообитающих беспозвоночных.

\section{Заключение}

Проведенные исследования по изучению биомассы почвенной мезофауны показали, что основу ее составляют дождевые черви, биомасса которых колеблется от 8,1 до 33,3 г/м², значительно меньше биомасса жесткокрылых. В ходе сравнительного анализа биомассы почвообитающих беспозвоночных животных в зависимости от биоразнообразия растительности модельных пойменных луговых экосистем установлено, что в обследованных биотопах в ряду пойменный луг нормального увлажнения, берег мелиоративного канала, мелиорированный польдерный луг, распаханный пойменный луг имеется зависимость между биомассой почвообитающих беспозвоночных и биоразнообразием растительности, описываемая квадратическим уравнением регрессии $Y=26,0-4,71 x+0,24 x^{2}$. Более достоверной является регрессионная модель с использованием кубического уравнения $Y=11,38-0,16 x^{2}+0,10 x^{3}$. При этом с ростом биоразнообразия растительности пойменных лугов наблюдается тенденция увеличения биомассы почвообитающих беспозвоночных.

\section{Библиографические ссылки}

1. Веремєєв В. Зоорізноманіття й структура комплексу дощових червів (Lumbricidae) заплавних луків Білоруського Полісся в умовах господарського використання / В. Веремєєв, Н. Синенок // Вісник Прикарпат. нац. ун-ту. Сер. Біологія. - 2007. - Вип. 7-8. - С. 123-125.

2. Биоразнообразие, количественные характеристики компонентов биоценозов водных и наземных экосистем Белорусского Полесья, их динамика / И. Ф. Рассашко, В. Н. Веремеев, Г. Г. Гончаренко и др. - Гомель : ГГУ им. Ф. Скорины, 2008. - 308 с.

3. Кипенварлиц А. Ф. Изменение почвенной фауны низинных болот под влиянием мелиорации и сельскохозяйственного освоения / А. Ф. Кипенварлиц. - Минск : Госиздатсельхозлит БССР, 1961. - $179 \mathrm{c}$.

4. Хотько Э. И. Почвенная фауна Беларуси. - Мн. : Навука і тэхніка, 1993. - 252 с.

5. Гиляров М. С. Учет крупных беспозвоночных (мезофауна) // Количественные методы в почвенной зоологии / Под ред. М. С. Гилярова, Б. Р. Стригановой. - М. : Наука, 1987. - С. 9-26.

6. Сапегин Л. М. Структура и функционирование луговых экосистем (экологический мониторинг) / Л. М. Сапегин, Н. М. Дайнеко. - Гомель : ГГУ им. Ф. Скорины, 2002. - 201 с.

7. Сапегин Л. М. Пойменные луга р. Сож пригорода г. Гомеля / Л. М. Сапегин, Н. М. Дайнеко. Гомель : ГГУ им. Ф. Скорины, 2007. - 115 с.

8. Методы определения продукции водных животных: Методическое руководство и материалы / Под ред. Г. Г. Винберга. - Мн. : Вышэйшая школа, 1968. - 245 с.

Надійшла до редколегії 10.10.2009 